\title{
Relationship between body mass index and waist-to-height ratio in childhood
}

\author{
João Carlos Pina Faria' (1)* , Camila Augusta Victorino' (D), Luciana Satiko Sawamura' (1), \\ Stephanie Ramos Coelho ${ }^{2}$ (D) Fabíola Isabel Suano-Souza ${ }^{\circledR} \mathbb{B}$, Roseli Oselka Saccardo Sarni ${ }^{2}$
}

\section{SUMMARY}

OBJECTIVE: To evaluate whether there is an association between the body mass index z-score and waist-to-height ratio of children and adolescents.

METHODS: This was a cross-sectional study conducted in a school in Santo André, SP, between June and August 2019. Body mass index was measured for all participants, adopting the z-score cutoff of +2 recommended by the World Health Organization. The waist-to-height ratio was determined in children over two years of age and considered abnormal when $\geq 0.5$. The qualitative variables are presented as absolute numbers and percentages. To compare qualitative data, we used the $\chi^{2}$ test or Fisher's exact test. Pearson's test was applied to assess the correlation between BMI and waist-to-height ratio. The level of significance adopted was $5 \%$.

RESULTS: The body mass index was calculated for 518 children and the waist-to-height ratio for 473 children. Regarding body mass index, $60.6 \%$ of the participants had normal weight, $3.1 \%$ were underweight, and $36.3 \%$ were overweight. overweight (24.7\%) and obesity $(22.7 \%)$ were more prevalent in adolescents. The waist-to-height ratio was abnormal in $50.5 \%$ of the sample. There was an increasing association between body mass index and waist-to-height ratio with age, according to the Pearson correlation coefficients for the age groups $<5$ years $(r=0.459 ; p<0.001), 5$ to 10 years $(r=0.687 ; p<0.001)$ and $>10$ years $(r=0.805 ; p<0.001)$.

CONCLUSION: There was a significant correlation between body mass index and waist-to-height ratio. This association was higher in adolescents. The waist-to-height ratio is easy to apply and may be useful as a predictor of cardiometabolic risk.

KEYWORDS: Body mass index. Waist-height ratio. Overweight. Child.

\section{INTRODUCTION}

The prevalence of overweight and obesity among children and adolescents has been growing significantly ${ }^{1}$. The percentage of obese children aged five to 19 years has increased ten-fold in the last 40 years $^{2}$. In 2010, there were 35 million overweight children in the world, and that number was expected to double in $2020^{3}$. In Brazil, one-third of children between five and nine years of age were overweight in $2010^{4}$.

Different anthropometric measures have been proposed to identify cardiometabolic risk (CMR) in children. Body mass index (BMI), although it does not provide any indication of the distribution of body fat, is the most commonly used parameter worldwides.
In adults, it is well established that increased abdominal fat, compared to BMI, is associated with greater $\mathrm{CMR}^{6}$. However, in children and adolescents, this association has not yet been fully established. A publication compiling data from five studies $(n=4,255)$ showed that the magnitude of associations for BMI and waist-to-height ratio (WHtR) in children and adolescents were similar in relation to the clustered CMR factors (lipid profile, HOMA-IR, and blood pressure) and performed better at higher BMI values. However, the accuracy of these anthropometric variables to classify the increased risk was $\operatorname{low}^{7}$. On the other hand, a recent study $(n=1,201)$ showed that the prevalence of individuals with metabolically unhealthy obesity in a pediatric population

\footnotetext{
${ }^{1}$ Centro Universitário Faculdade de Medicina do $A B C$ - Santo André (SP), Brazil.

2Universidade Federal de São Paulo - São Paulo (SP), Brazil.

*Corresponding author: jocapf79@gmail.com

Conflicts of interest: the authors declare there are no conflicts of interest. Funding: none.

Received on December 02, 2020. Accepted on December 13, 2020.
} 
was high and that the $\mathrm{WHtR}$ was an independent predictor of this form of obesity ${ }^{8}$.

Most authors correlate WHtR $\mathrm{p} \geq 0.5$ with increased abdominal adiposity and CMR'. Because the cutoff value is the same for everyone, the $\mathrm{WHtR}$ is easy to interpret ${ }^{10}$.

A national study with children aged four to seven years showed that when the normal weight group was evaluated using indicators of abdominal adiposity, the prevalence of abnormal nutritional status was higher than that when evaluated by BMI/ age $^{11}$. However, this association between BMI and WHtR in the identification of excess weight has not yet been fully elucidated for all age groups in Brazil. The objective of this study was to evaluate whether there is an association between the BMI z-score and WHtR of children and adolescents.

\section{METHODS}

This cross-sectional study was conducted at Instituição Cidade dos Meninos Maria Imaculada ("Cidade dos Meninos Maria Imaculada" Rehabilitation Center) in the municipality of Santo André, state of São Paulo (SP), Brazil, between June and August 2019.

All participants were invited to enroll in the study.

Children who did not want to participate, those whose family members did not sign the consent form and those with short stature were excluded. A systematic review suggested that there is a risk of misinterpretation of the $\mathrm{WHtR}$ in children with short stature ${ }^{12}$.

Height was measured using a vertical stadiometer, graduated in centimeters and millimeters. Weight was measured using a digital scale with a precision of 10 grams. BMI was calculated by dividing the weight in kilograms by the height in meters squared.

Waist circumference was assessed for children aged two years or older, using a centimeter and millimeter graduated tape measure. The tape measure was placed at the midpoint between the iliac crest and the last rib. This anatomical point has the strongest correlation with abdominal adiposity ${ }^{13}$. The WHtR was obtained by dividing the waist circumference in centimeters by the height.

BMI was classified by BMI/age according to sex, adopting the z-score cutoff of +2 recommended by the World Health Organization ${ }^{14}$. Thus, children under five years old with overweight and obesity and children older than five with obesity and severe obesity were included in the group with excess weight. The $\mathrm{WH}$ tR was considered abnormal when the value was $\geq 0.5^{10}$.

A total of 23 children were excluded from the analysis due to their short stature. The BMI was calculated for 518 children. The WHtR was calculated for children aged 24 months or older $(\mathrm{n}=473)$. Three children had no waist circumference recorded because they missed the days that the evaluators were at the school, and thus, the $\mathrm{WHtR}$ was not calculated for these children, only the BMI.

The data were entered into an Excel spreadsheet (Microsoft) and analyzed using Epi Info ${ }^{\mathrm{TM}}$, version 7.2.2.6. The qualitative variables are presented as absolute numbers and percentages. To compare the qualitative data, we used the $\chi 2$ test or Fisher's exact test. The level of significance was set at $5 \%$. Pearson's test was used to correlate BMI with $\mathrm{WHtR}$.

The study was approved by an ethics and research committee, opinion number 3.058.583, CAAE: 02670518.7.0000.0082

\section{RESULTS}

Table 1 shows the general characteristics of the children in the study. The mean age was $72.5 \pm 12.2$ months (range 9 to 186 months), with a slight predominance of males (288; 53.2\%).

Regarding nutritional status, 314 (60.6\%), 188 (36.3\%), and $16(3.1 \%)$ were classified as normal weight, above the ideal weight (risk of overweight, overweight, obesity, and severe obesity) and thin, respectively. The WHtR was rated abnormally for 239 children (50.5\%) (Table 1).

Overweight was present in 19\% of children under the age of two years, $9.1 \%$ of children from two to five years, $15.3 \%$ of children from five to ten years and $22.7 \%$ of children older than 10 years. Among the adolescents, the prevalence of overweight was also high (24/24.7\%). When comparing the prevalence of overweight and abnormal WHtR by sex in each age group, there was no significant difference (Table 2).

When correlating BMI, using the $\mathrm{z}$-score +2 as the cutoff point, with the $\mathrm{WHtR}$, using 0.5 as the cutoff point, the correlation between the two increased with age. The Pearson correlation coefficients were $0.459,0.687$, and $0.805(\mathrm{p}<0.001)$ in children younger than five years, children five to ten years old, and children older than 10 years, respectively (Figure 1). There was no difference between sexes (male: $0.535, \mathrm{p}=0.000$; female: $0.589, \mathrm{p}=0.000$ ).

\section{DISCUSSION}

The number of children above the ideal weight was ten times higher than the number of children classified as malnourished (36.3 vs. $3.1 \%$ ). Studies have indicated an increase in the prevalence of excess weight in children, but the observed values in this study were above those described in Brazilian population studies $^{2,3}$.

Almost half of the adolescents evaluated were above the ideal weight. Data from the 2016 Brazilian Institute of Geography and Statistics showed that $23 \%$ of Brazilian adolescents had excess 
Table 1. General characteristics and nutritional status of the children included in the study.

\begin{tabular}{|c|c|c|}
\hline & $n$ & $\%$ \\
\hline \multicolumn{3}{|l|}{ Gender $(n=518)$} \\
\hline Male & 272 & 52.5 \\
\hline Female & 246 & 47.5 \\
\hline \multicolumn{3}{|l|}{ Age $(n=518)$} \\
\hline Children under 2 years old & 42 & 8.1 \\
\hline $2-5$ years & 209 & 40.3 \\
\hline $5-10$ years & 170 & 32.8 \\
\hline 10 years or more & 97 & 18.7 \\
\hline \multicolumn{3}{|c|}{ Nutritional diagnosis body mass index z-score $(n=518)$} \\
\hline Marked thinness & 5 & 1 \\
\hline Thinness & 11 & 2.1 \\
\hline Normal weight & 314 & 60.6 \\
\hline Risk of overweight & 57 & 11 \\
\hline Overweight & 77 & 14.9 \\
\hline Obesity & 41 & 7.9 \\
\hline Severe obesity & 13 & 2.5 \\
\hline \multicolumn{3}{|l|}{ Waist-to-height ratio $(n=473)$} \\
\hline$<0.5$ & 234 & 49.5 \\
\hline$\geq 0.5$ & 239 & 50.5 \\
\hline
\end{tabular}

Table 2. Nutritional diagnosis by body mass index and classification of waist-to-height ratio by sex and age group.

\begin{tabular}{|c|c|c|c|c|c|c|}
\hline \multirow{2}{*}{ Age } & \multirow{2}{*}{ Classification } & \multicolumn{2}{|c|}{ Male } & \multicolumn{2}{|c|}{ Female } & \multirow[t]{2}{*}{ p-value } \\
\hline & & $\mathrm{n}$ & $\%$ & $n$ & $\%$ & \\
\hline \multicolumn{7}{|c|}{ Body mass index (BMI) } \\
\hline$<2$ years & No excess weight & 20 & 47.6 & 14 & 33.3 & \multirow{2}{*}{$0.68 *$} \\
\hline$(n=42)$ & Excess weight & 6 & 14.3 & 2 & 4.8 & \\
\hline $2-5$ years & No excess weight & 97 & 45.9 & 93 & 43.1 & \multirow{2}{*}{$0.74 * *$} \\
\hline$(n=209)$ & Excess weight & 11 & 5.7 & 8 & 5.3 & \\
\hline $5-10$ years & No excess weight & 82 & 48.2 & 62 & 36.5 & \multirow{2}{*}{$0.42 * *$} \\
\hline$(n=170)$ & Excess weight & 12 & 7.1 & 14 & 8.2 & \\
\hline$\geq 10$ years & No excess weight & 35 & 36.1 & 40 & 41.2 & \multirow{2}{*}{$0.81 * *$} \\
\hline$(n=97)$ & Excess weight & 9 & 9.3 & 13 & 13.4 & \\
\hline \multicolumn{7}{|c|}{ Waist-to-height ratio (WHtR) } \\
\hline $2-5$ years & $<0.5$ & 24 & 11.5 & 28 & 13.5 & \multirow{2}{*}{$0.47 * *$} \\
\hline$(n=208)$ & $\geq 0.5$ & 83 & 39.9 & 73 & 35.1 & \\
\hline $5-10$ years & $<0.5$ & 72 & 42.6 & 51 & 30.2 & \multirow{2}{*}{$0.28 * *$} \\
\hline$(n=169)$ & $\geq 0.5$ & 22 & 13 & 24 & 14.2 & \\
\hline$\geq 10$ years & $<0.5$ & 26 & 27.1 & 33 & 34.4 & \multirow{2}{*}{$0.81 * *$} \\
\hline$(n=96)$ & $\geq 0.5$ & 18 & 18.7 & 19 & 19.8 & \\
\hline
\end{tabular}

* $\mathrm{p}$ : significance level by Fisher's exact test; **p: significance level by the chi-squared test. 


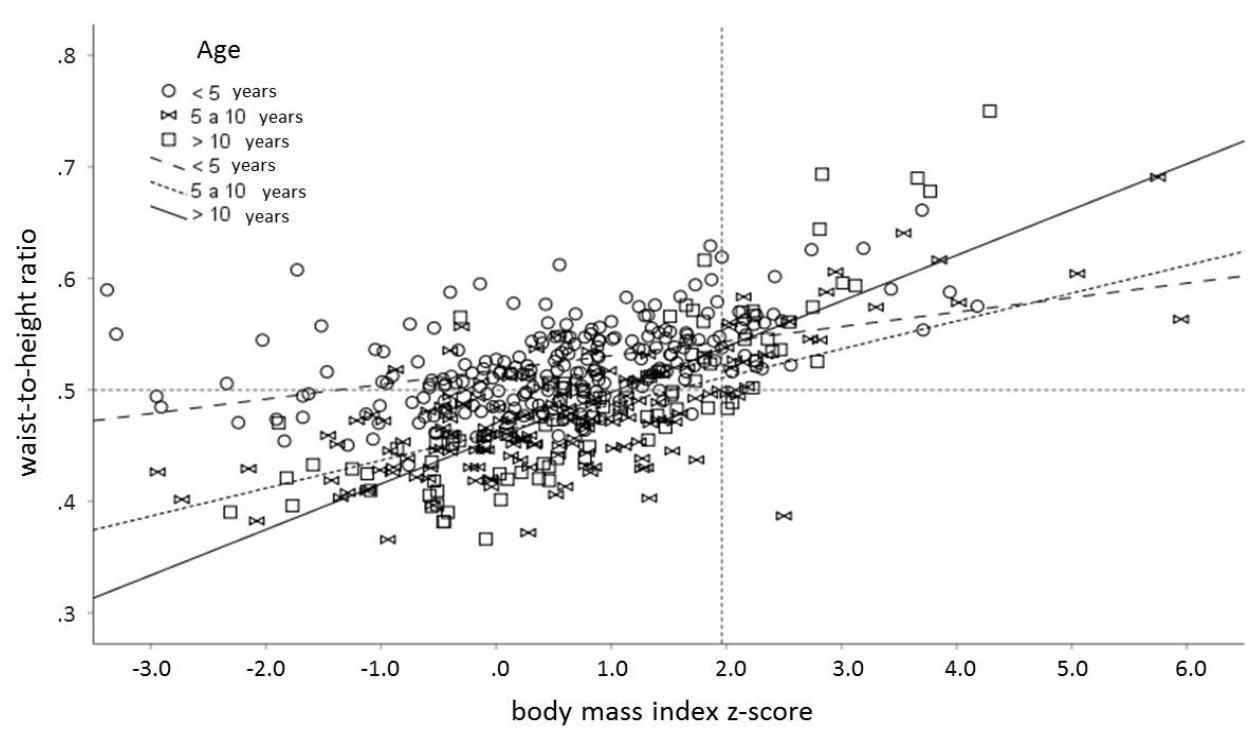

Figure 1. Correlation between body mass index z-score and waist-to-height ratio.

weight ${ }^{15}$. In 2015, a study conducted in Campinas, SP, found that 8.4 and $16.8 \%$ of adolescents were obese and overweight, respectively $^{16}$. In the city of Ribeirão Preto, SP, in 2016, 30.9\% of adolescents were overweight or obese $\mathrm{e}^{17}$. Adolescents more frequently consume ultra-processed foods, favoring the emergence of obesity ${ }^{18}$.

The correlation between BMI z-score and WHtR was stronger with increased age, ranging from $r=0.459$ for children under 5 years of age to $r=0.805$ for children over 10 years of age. A significant number of children and adolescents with a BMI z-score lower than +2 had a WHtR greater than 0.5 (Figure 1). These findings reinforce the importance of using both measurements in the pediatric age group, especially in adolescents.

Meta-analysis showed that both BMI and WHtR can be useful to define obesity in the pediatric age group when more sophisticated techniques, such as dual-energy X-ray absorptiometry, are not available ${ }^{19}$.

The increase in WHtR is related to android obesity. We did not find differences between sexes based on WHtR. A study conducted in the state of Minas Gerais with prepubertal children found a higher prevalence of android obesity in girl $s^{20}$. Android obesity increases WHtR measurements and is associated with higher $\mathrm{CMR}^{21}$. In Brazil, female children and adolescents practice less physical activity than do boys, a factor that may contribute to the risk of obesity in this group ${ }^{22}$.

A Brazilian study conducted with children aged six to ten years suggested that the WHtR could be used in conjunction with BMI to more reliably assess body fat distribution ${ }^{23}$. A survey conducted in Colombia with 1,919 adolescents showed that the use of BMI alone is not sufficient to predict $\mathrm{CMR}^{24}$. The introduction of WHtR in the pediatric routine would not increase the visit duration by much, as only an additional measurement of waist circumference would be required. In children and adolescents with excess weight, an abnormal WHtR contributes to the identification of $\mathrm{CMR}^{25}$.

A limitation of this study was the evaluation of a single school in the municipality of Santo André, SP, thus not allowing us to extrapolate the data to the general population.

\section{CONCLUSION}

The prevalence of excess weight in the study population was higher than that described in population surveys, especially among adolescents. The WHtR is a simple, inexpensive, highly reproducible, and accurate tool for the prevention, control, and identification of childhood obesity and should be applied. The correlation between BMI z-score and $\mathrm{WHtR}$ increased with age, suggesting the importance of measuring both parameters, especially in adolescents.

\section{AUTHORS" CONTRIBUITION}

JCPF: Conceptualization, Data Curation, Formal Analysis, Project Administration, Writing - Original Draft. CAV: Data Curation, Formal Analysis. LSS: Data Curation, Formal Analysis. SRC: Data Curation. FISS: Formal Analysis, Writing - Original Draft. ROSS: Formal Analysis. Writing - Original Draft. 


\section{REFERENCES}

1. Wang Y, Monteiro C, Popkin BM. Trends of obesity and underweight in older children and adolescents in the United States, Brazil, China, and Russia. Am J Clin Nutr. 2002;75(6):971-7. https://doi.org/10.1093/ajcn/75.6.971

2. NCD Risk Factor Collaboration (NCD-RisC). Worldwide trends in body-mass index, underweight, overweight, and obesity from 1975 to 2016: a pooled analysis of 2416 population-based measurement studies in 128.9 million children, adolescents, and adults. Lancet. 2017;390(10113):2627-42. https://doi. org/10.1016/S0140-6736(17)32129-3

3. de Onis M, Blössner M, Borghi E. Global prevalence and trends of overweight and obesity among preschool children. Am J Clin Nutr. 2010;92(5):1257-64. https://doi.org/10.3945/ ajcn.2010.29786

4. Brasil. Instituto Brasileiro de Geografia e Estatísticas. Pesquisa de orçamentos familiares 2008-2009. Antropometria e estado nutricional de crianças, adolescentes e adultos no Brasil. Rio de Janeiro: IBGE; 2010.

5. Batson YA, Teelucksingh S, Maharaj RG, Cockburn BN. A crosssectional study to determine the prevalence of obesity and other risk factors for type 2 diabetes among school children in Trinidad, west indies. Paediatr Int Child Health. 2014;34(3):17883. https://doi.org/10.1179/2046905514Y.0000000116

6. Corrêa MM, Facchini LA, Thumé E, Oliveira ERA, Tomasi E. The ability of waist-to-height ratio to identify health risk. Rev Saude Publica. 2019;53:66. https://doi.org/10.11606/ s1518-8787.2019053000895

7. Sardinha LB, Santos DA, Silva AM, Grøntved A, Andersen LB, Ekelund U. A Comparison between BMI, waist circumference, and waist-to-height ratio for identifying cardio-metabolic risk in children and adolescents. PLoS One. 2016;11(2):e0149351. https://doi.org/10.1371/journal.pone.0149351

8. Genovesi S, Antolini L, Orlando A, Gilardini L, Bertoli S, Giussani M, et al. Cardiovascular risk factors associated with the metabolically healthy obese (mho) phenotype compared to the metabolically unhealthy obese (MUO) phenotype in children. Front Endocrinol (Lausanne). 2020;11:27. https:// doi.org/10.3389/fendo.2020.00027

9. Brannsether B, Roelants M, Bjerknes R, Júlíusson PB. Waist circumference and waist-to-height ratio in Norwegian children 4-18 years of age: reference values and cut-off levels. Acta Paediatr. 2011;100(12):1576-82. https://doi. org/10.1111/j.1651-2227.2011.02370.x

10. Ashwell $M$, Hsieh SD. Six reasons why the waist-to-height ratio is a rapid and effective global indicator for health risks of obesity and how its use could simplify the international public health message on obesity. Int J Food Sci Nutr. 2005;56(5):303-7. https://doi.org/10.1080/09637480500195066

11. Vieira SA, Ribeiro AQ, Hermsdorff HHM, Pereira PF, Priore SE, Franceschini SDCC. Waist-to-height ratio index or the prediction of overweight in children. Rev Paul Pediatr. 2017;36(1):7. https://doi.org/10.1590/1984-0462/;2018;36;1;00002

12. Magalhães EI, Sant'Ana LF, Priore SE, Franceschini SC. Perímetro da cintura, relação cintura/estatura e perímetro do pescoço como parâmetros na avaliação da obesidade central em crianças [Waist circumference, waist/height ratio, and neck circumference as parameters of central obesity assessment in children]. Rev Paul Pediatr. 2014;32(3):273-81. https://doi. org/10.1590/0103-0582201432320
13. Sant'Anna MS, Tinoco AL, Rosado LE, Sant'Ana LF, Mello AC, Brito IS, et al. Body fat assessment by bioelectrical impedance and its correlation with different anatomical sites used in the measurement of waist circumference in children. J Pediatr (Rio J). 2009;85(1):61-6. https://doi.org/10.2223/JPED.1871

14. World Health Organization. The WHO child growth standards. Genebra: WHO; 2020 [cited on Mar. 10, 2020]. Available from: https://www.who.int/growthref/en/

15. Instituto Brasileiro de Geografia e Estatistica(IBGE). Pesquisa nacional de saúde do escolar: 2015/1BGE, Coordenação de População e Indicadores Sociais. Rio de Janeiro: IBGE, 2016. 132 p.

16. Brevidelli MM, Coutinho RMC, Costa LFV, Costa LC. Prevalence and factors associated with overweight and obesitu among adolescents of a public school. Rev Bras Promoç Saude. 2015;28(3): 379-86. https://doi.org/10.5020/18061230.2015. p379

17. Pinto RP, Nunes AA, de Mello LM. Analysis of factors associated with excess weight in school children. Rev Paul Pediatr. 2016;34(4):460-8. https://doi.org/10.1016/j.rpped.2016.04.002

18. Associação Brasileira para o Estudo da Obesidade e Síndrome Metabólica. Diretrizes brasileiras de obesidade. 4th ed. São Paulo: ABESO; 2016 [cited on Oct. 3, 2020]. Available from: http:// www.abeso.org.br/uploads/downloads/92/57fccc403e5da. pdf

19. Martin-Calvo N, Moreno-Galarraga L, Martinez-Gonzalez MA. Association between body mass index, waist-to-height ratio and adiposity in children: a systematic review and meta-analysis. Nutrients. 2016;8(8):512. https://doi.org/10.3390/nu8080512

20. Filgueiras MS, Vieira SA, Fonseca PCA, Pereira PF, Ribeiro AQ, Priore $S E$, et al. Waist circumference, waist-to-height ratio and conicity index to evaluate android fat excess in Brazilian children. Public Health Nutr. 2019;22(1):140-6. https://doi. org/10.1017/S1368980018002483

21. Delgado EMG, Urrego CLD, Lesmes DCQ. Waist-to-height ratio and its relation with cardiometabolic risk factors in children from Bucaramanga, Colombia. Nutr Hosp. 2017;34(5):133844. https://doi.org/10.20960/nh.1059

22. Souza FJR, Vasconcelos EO, Lopes JPN, Letieri RV, Pontes Júnior JAF. Active, dedentary behavuior and food habits of teenagers froma a country town in Ceará, Brazil. Conexões. 2015;13:114-28. https://doi.org/10.20396/conex.v13i1.2152

23. Ricardo GD, Gabriel CG, Corso AC. Anthropometric profile and abdominal adiposity of school children aged between 6 and 10 years in southern Brazil. Rev Bras Cineantropom Desempenho Hum. 2012;14:636-46. http:// doi.org/10.5007/1980-0037.2012v14n6p636

24. García-Hermoso A, Agostinis-Sobrinho C, Camargo-Villalba GE, González-Jiménez NM, Izquierdo M, Correa-Bautista $J E$, et al. Normal-weight obesity is associated with poorer cardiometabolic profile and lower physical fitness levels in children and adolescents. Nutrients. 2020;12(4):E1171. http:// doi.org/10.3390/nu12041171

25. Barroso AT, Marins LB, Alves R, Gonçalves ACS, Barroso SG, Rocha GS. Associação entre a obesidade central e a incidência de doenças e fatores de risco cardiovascular. Int J Cardiovasc Sci. 2017;30(5):416-24. http://doi. org/10.5935/2359-4802.20170073 